\section{A CASE OF ADIPOSIS DOLOROSA.}

\section{(With Illustrations.)}

BY W. HALE WHITE, M.D., F.R.C.P., Physician to and Lecturer on Medicine at Guy's Hospital.

Adiposis Dolorosa is the name first epplied by Dercum ${ }^{1}$ in 1892 to an assemblage of clinical symptoms which apparently occur in association sufficiently constantly to be considered as a separate disease. Dercum himself has seen two fatal cases; unfortunately the assistant, by mistake, threw away all the organs reserved for histological examination, but as in one the thyroid was small, indurated, and infiltrated, with calcareous matter in each lobe; and in the other the thyroid, although larger than normal, was much calcified, especially in the right lobe, it may be that adiposis dolorosa should be called a disease of the thyroid gland, but our knowledge does not at present allow of a more definite opinion.

The best general accounts of the disease are those by by Collins ${ }^{2}$ and Dercum, ${ }^{3}$ and the last author when he named the disease gave an excellent description of 3 cases. Spiller ${ }^{4}$ also has recorded 3 cases which are particularly interesting; because the first was in a young adult. Other American authors have described cases, one of the latest is that recorded by Eshner. ${ }^{5}$ Putting together the symptoms of all the cases I have been able to read and my own case, the following appears to be a fair description of them.

So far all the observed cases have been in women The onset is usually noticed between the ages of 40 and 6o. Some of the patients have been drunkards, and some have had syphilis. The first thing noticed is that fatty masses appear on the trunk or limbs; these are sometimes symmetrical. Fresh masses appear, and at the same time the patient becomes generally obese, so that in a fully developed case she is enormously fatin one fatal case the fat of the abdominal wall was 7 inches thick-but even then here and there there are large lumps. The hands, feet, and face have escaped in all the recorded cases. These points are admirably shown in the

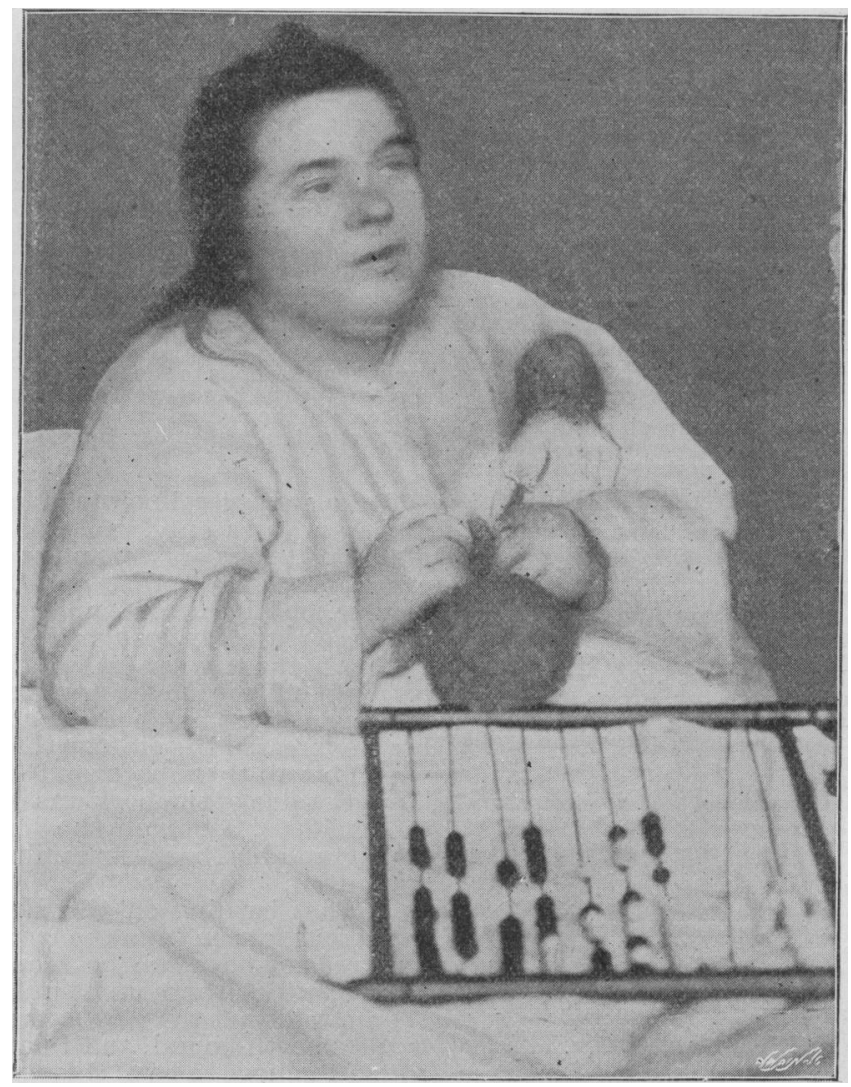

Fig. 3.-During one of her mental attacks in which she imagines ste sharp, burning, or scalding, and is frequently paroxysmal, but then there is usually slight pain between the paroxysms. The patient often complains early in the course of the disease of a sense of coldness, and if examined when the disease is fully developed is usually found to have greatly diminished powers all over, or almost all over, her body of appreciating pain, touch, heat, and cold. This diminution of sensation varies in different parts of the body in the same patient; in some places it amounts to absolute loss of one or more of the varieties of sensation. Often the masses of fat are intensely tender when grasped. My patient shrieks when she is gripped.

The muscular power is very feeble ; my patient can hardly walk, and with either hand can only move the dynamometer through 5 degrees.

In some cases there has been great mental dulness, and one of Dercum's patients died demented. My patient goes out of her mind temporarily. Headache is a common symptom. Herpes, hæmatemesis, epistaxis, early menopause, slight pigmentation of the skin, atrophy of the muscles of the hand, and reaction of degeneration of them have all been described as occasional symptoms.

Dercum extracted a piece of the fat during life, and found it to resemble the embryonic type, and one nerve fibre examined showed dense connective tissue with a multiplication of nuclei. He suggests that the disease is a trophic neurosis.

In some cases the disease has been complicated by bronchitis. The mueous membranes, the appetite, the pulse, the temperature, the urine, the speech, the hair, and the optic discs, all appear healthy. In one case the tongue was a little large, but not strikingly so. The skin is usually normally moist. The special senses may be slightly blunted. There is no œdema.

In most cases the disease is progressive. One fatal case died from pulmonary œdema, bronchitis, hypostatic congestion, and all the effects of backward pressure; the other died demented. One case appeared to improve on thyroid, but in my case administration of thyroids did no good.

I append an account of $\mathrm{my}$ patient. For help in preparing is a child. lumps hanging from each arm hould be noticed. Dercum's first patient, of whom a photograph may be found in his and Collins's articles, also had symmetrical masses in this position, but a friend tells me that in Uganda, where the native men fatten their wives because they consider fat beautiful, huge masses form in this position. In Spiller's first case the patient was seen early, so that the excess of fat was only evident on one lower extremity and part of the trunk. On taking hold of one of these masses of fat they feel not unlike a varicocele. It has been suggested to me that some of the fat women in travelling shows are examples of adiposis dolorosa.

Pain is a striking symptom. It is usually noticed as soon as and it may be before the faity masses; it may be felt in parts that do not become fat. It may be very severe, is often clerk, and also to him and Mr. E. J. Claxton for the photographs. The clothes in Fig. I are pinned up above the knees; the masses of fat end so sharply at the ankles, that she looks as though she had on baggy trousers. It will be noticed that she is unlike the other cases in that the disease began early in life. She is only now 22 years old and she has had congenital syphilis. Dr. P. A. Colmer, of Yeovil, under whose care she has often been, writes to me: "I have tried every form of treatment, including thyroid, without any benefit. She has been in the asylum once or twice. There is no doubt her parents had syphilis, and her grandparents on the mother's side are rather peculiar people. She has been in several hospitals but all with no benefit.

A. F., aged 22, was admitted into Guy's Hospital, July 29th, 18 under Dr. Hale White.

All the members of her family are healthy. There is no one related to the patient who has suffered in the same way 
Personal History. - Between 11 and 12 years of age the patient began to get stout. The legs first began to enlarge just above the ankle. She had pain in the epigastric region; this was quite independent of meals, and is said to have been "a constant, gnawing, aching pain." There was similar pain with tenderness in the lower lumbar region. By the end of twelve months she had increased in bulk in all parts of her body, and at the age of 13 she weighed 20 stone. At this age a soft swelling appeared on the left side of the neck, anteriorly and about half way down. It bur and for some weeks discharged a dark brown fluid. It then healed. At the age of ${ }^{5}$ the patient's mind began to be affected. She lost conscious control of herself and her actions, and was very violent. She remained in this condition for several weeks and then recovered, but had no recollection of what happened during the time. Since then she has had repeated attacks of a similar nature, except that she is not violent. ther mental condition is that of a child, and she plays with toys etc. This condition may last a week or so. She has had intervals of four or five months between the attacks, but during the last year they have become more frequent, the interval between them being about a fortnight. She knows when an attack is approaching. She "feels something rising from the body into the head." These attacks often commence with an epileptiform fit. She loses consciousness and falls, often hurting herself. She then apparently has convulsions, the fit lasting a few minutes. After this she is quiet, but does not return to her proper senses for some days. She has no recollection of what she has said or done during this time. At the age of 16 she went to a doctor, who treated her with thyroids. About this time her eyes were affected. She had sharp shooting pains in them, and soon became almost blind. She could only distinguish light from darkness. She was again treated with thyroids, and recovered the sight of one eye in about four months, but the left eye remained blind for some time longer. During this time, when more or Jess blind, she

recovered.

At the age of 20 she still weighed 20 stone. Ever since the beginning of the illness she had had pain in the abdomen, pelvic region, lumbar region, head, eyes, and limbs. She always describes it as an "aching lways of the same nature, and is not generally in more than one place at a time. It often lasts for several hours, and then disappears for a day or wo. The mental attacks are generally preceded by pain in the head and eyes, and followed by pain in the abdomen. Her menstrual periods began at the age of 12 , and occur at intervals of five or six weeks. She
perspires a good deal, and is not at all susceptible to cold. She complains

Condition on Admission.-She is excessively stout on all parts of the body except the hands, feet, face, neck, and head. She weighs r $9 \frac{1}{2}$ stone. Large masses of subcutaneous fat hang from the posterior part of th limbs, especially the arms and thighs, but the limb is, in addition to this, lar all round. There is no pitting anywhere on pressure, the face torge and a little fat, but the fat here is quite inconsiderable compare to that on the body and limbs. The hair is well grown, and is not healthy, the skin is pale but not abnormally pigmented; it shows several atrophic lines, and is on the abdomen thrown into folds from severalls of fat; it is moist. The eyes are rather large, and have a dull expression. There is a small white opaque patch at the lower margin of the cornea in each eze. The iris of both eyes is a little irregular a though from old iritis. The optic discs are healthy, except that perhaps the vessels are a little small. The hands and feet are small There are some scars on the upper lip near the nose, and at the angle of the mouth, which the patient says are due to sores, and he mother says she had a rash not long after birth. It is quite obvious that she has had congenital syphilis, The circulatory and respiratory systems appear normal. There is a slight mucous and respiratory systems appear normal. There is a slight mucous the morning when waking. The tongue is perhaps a little large, but ver little. The teeth are rather decayed. She has lost three or four, which she says have dropped out. The mouth and fauces appear absolutely healthy. She has a poor appetite, but has no alimentary disturbance There is nothing abnormal to be made out on feeling the abdomen. She says that occasionally there is a discharge of whitish, thick, foul-smelling fluid from the umbilicus. The urine is healthy, except that it contains some phosphates, mucus, and epithelial cells. The voice is perfectly normal, but she speaks a little slowly, not more so than many health people. All over the body, face, and limbs sensation to touch, pain, and the prick of a pin nor tell the difference between iced and hot water. The masses of fat are very tender, so that the patient cannot bear them to be only move the dynamometer through 5 degrees, and she walks with well be from sheer weakness.

The following measurements were taken while she was in the hospital : Just above the umbilicus the circumference was 50 inches : at the axillæ it was $40 \frac{3}{4}$. The left arm was 20 , the right $20 \frac{3}{2}$, the middie of the right thigh 32 and of the right leg $20 \frac{1}{2}$. After she had been in a few days she hoise, af her mental attacks. Fin a made became like a child, said she was 5 years old played with a doll and number of toys, and gave her wrong name. After a sleep this passed off, and she was herself again.

She remained under observation in the hospital for six weeks. Ther was no change in her condition. During this time she had two menta attacks, in which she becane quite childlike. An exclusively proteid die was tried, but it did not diminish her weight. Treatment by thyroid gland preparations was begun, but after receiving Dr. P. A. Colmer's her history was correct we communicated with her parents and grandparents.

Nervous Diseal Journal of Medical Sciences, 1892, p. 52r. 2 Textbook of Medicine, vol. xi. 4 Medical News, February 26th, 1898. 5 Philadelphia Medical Journal, October 8th, 1898 .

\section{THREE CASES OF SHARK BITE.}

BY WILLIAM BRYCE ORME, M.R.C.S.ENG.,

P.M.O., Port Said.

(With Illustrations.)

THE following account of three cases of shark bite which occurred here on August 8th, 1899, may be of interest :

CASE I.-Arab boy, aged 13, admitted 8.30 A.M. The outer aspect of the left leg presented an enormous wound ro inches in length, with its con vexity backwards. The inner aspeet showed three much smaller and pletely laid open on its external aspect, so that by slightly bending the plimb inwards one could obtain a perfect view of the interior of the joint with its semilunar cartilages. The peroneus longus tendon was divided in two places, and the tendo Achillis partially torn through. After suturing the tendons I inserted three large drainage tubes in various parts, and then united the skin wounds. The joint was left open, al Unfortunatelr the lower wound suppurated freely, a large portion of the skin, 6 inches long, sloughing. The joint, which was at first doing well, and had healed up, soon became distended with pus, so that it had at a subsequent operation to be freely opened on both sides and a large drainsubsequent operation to be freely opened on both sides and a large drainage tube inserted. The boy is still alive, but his further history

CASE 1I.-Arab boy, aged I. Admitted 9.30 A.M. About one dozen lacerated wounds on the dorsal aspect of right forearm, wrist, and hand varying from $\frac{1}{2}$ to $3^{\frac{3}{2}}$ inches in length, and not involving

He was discharged quite cured at the end of the month. admitted II.30 A.M. It is not necessary for me to describe this case, as the illastrations do this for me. However, large masses of the erector spinæ were torn and lacerated, so that they had to be cut away. A long drainage tube was placed under the large flap, and a total of 86 stitehes inserted. A few days later a small portion of skin 33 inches in length was at the time of the accident floating on his back, and the large back wound corresponds to the lower jaw of the animal. The great wonder, considering the huge superficial extent of the injury, is that no ribs were broken and the pleural cavity not opened. The boy was discharged perfectly cured on September 2 nd.

REMARKS.

There are several points of interest in these cases: (1) That during lo years only two other cases have occurred at Port Said (one two years ago and one six years ago). Of course I cannot be certain that no other case had been treated in private, but I think it unlikely, as all serious cases of the kind are naturally brought to hospital.

(2) All three boys (as in the two preceding cases) were bathing off the Mediterranean shore, although none were bathing at the same place or at the same time. Many people have expressed the opinion that it must have been one shark which bit all three boys, and I think this very likely.

(3) Not one of the boys was out of his depth at the time of the accident, although the little boy who is figured in the photograph had been swimming out a few minutes before he bitten.

(4) That bathing off the Mediterranean shore is not very dangerous is seen from the fact that during the hot weather hundreds of boys can be seen bathing daily from the very place at which these unfortunate boys were bitten.

I am told that the most common kind of shark off this coast is the smooth-hound, and I have myself seen two specimens which I believe to be of this variety. From the scanty information I can gain from the boys I fancy it must have been a smooth-hound that bit them. Hammer-headed sharks are also occasionally seen here.

It is said by many old residents in Port Said that there is no danger in bathing in the harbour or canal, as sharks never come where the common porpoise ( phocana communis) abounds, as it certainly does in both. I am now told, however, that in a small village about eight miles from here numbers of sharks are caught in a small creek conneeting the sea with Lake Menzaleh, which also abounds in porpoises. From the subjoined extract from a newspaper it appears that sharks have come through the canal, and 1 see no reason why they should not still continue to do so.

Sharks were almost unknown in the Adriatio until the Suez Canal was opened. Now the harbours of Fiume and Pola are so infested with then that residents dare no longer bathe in the open sea.

By Ruyal decree, dated October 28th, a State Institute of Serumtherapy, Vaccination, and Bacteriology, to bear the name of Alfonso XIII, has been created in Madrid. The new institute is organised on the lines of the Institut Pasteur. 


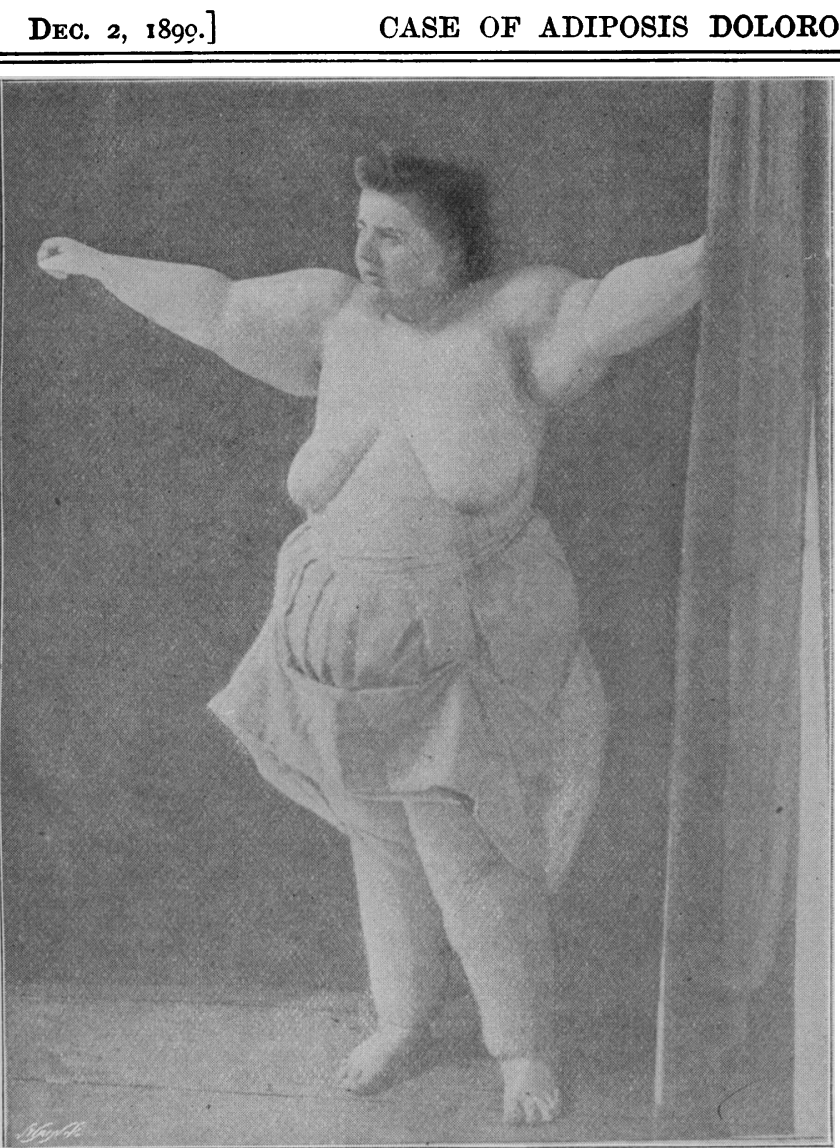

Fig. r.-A. F., aged 22. Front view.

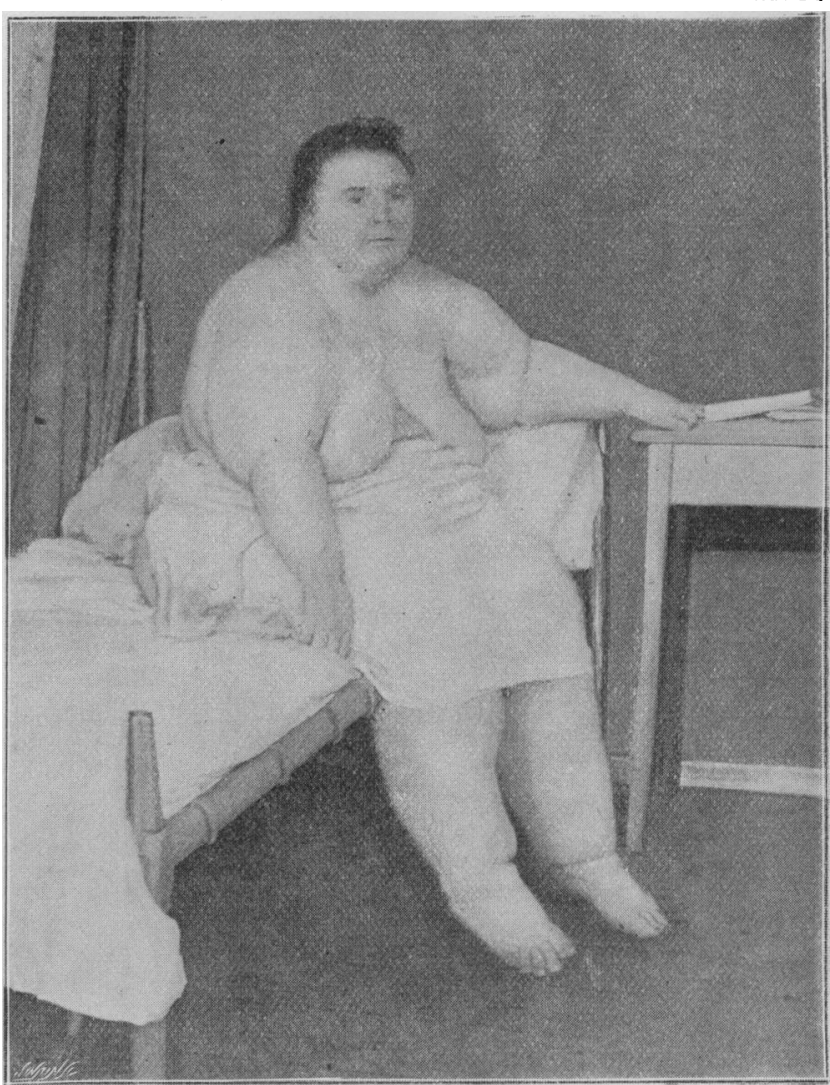
TO ILLU:TRATE D3. HALE WHITE'S PAPER (page 1533!
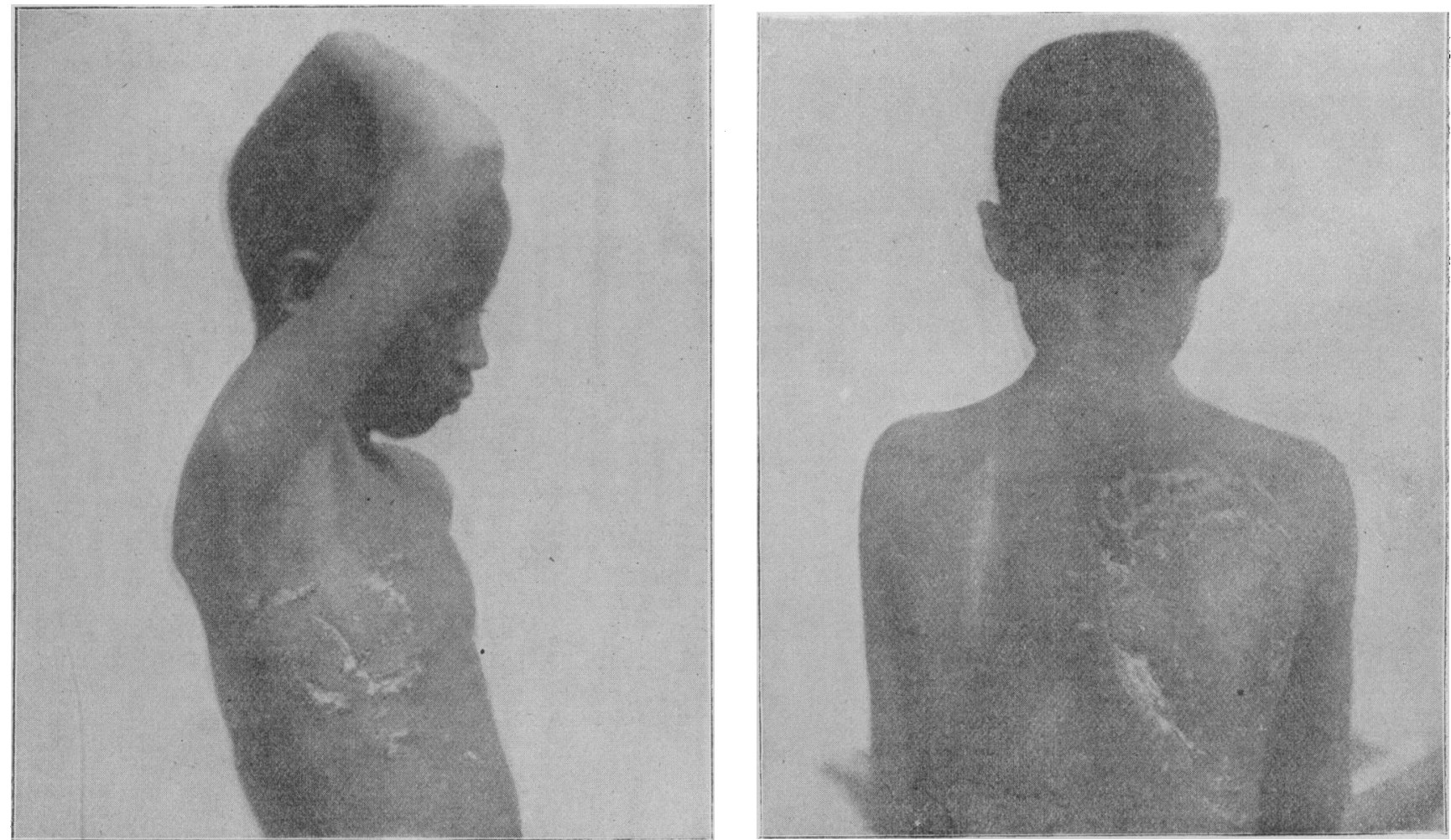

Fig. r. - Scar of shark bite. 